\title{
Not Good, but Not All Bad: Dehydration Effects on Body Fluids, Organ Masses, and Water Flux through the Skin of Rhinella schneideri (Amphibia, Bufonidae)
}

\author{
Rodolfo C. O. Anderson ${ }^{1, *}$ \\ Rafael P. Bovo ${ }^{1}$ \\ Carlos E. Eismann ${ }^{2}$ \\ Amauri A. Menegario ${ }^{2}$ \\ Denis V. Andrade ${ }^{1}$ \\ ${ }^{1}$ Departamento de Zoologia, Instituto de Biociências, \\ Universidade Estadual Paulista, Rio Claro, São Paulo, Brazil; \\ ${ }^{2}$ Centro de Estudos Ambientais, Universidade Estadual \\ Paulista, Rio Claro, São Paulo, Brazil
}

Accepted 11/10/2016; Electronically Published 1/3/2017

\begin{abstract}
Because of their permeable skin, terrestrial amphibians are constantly challenged by the potential risk of dehydration. However, some of the physiological consequences associated with dehydration may affect aspects that are themselves relevant to the regulation of water balance. Accordingly, we examined the effects of graded levels of dehydration on the rates of evaporative water loss and water absorption through the skin in the terrestrial Neotropical toad, Rhinella schneideri. Concomitantly, we monitored the effects of dehydration on the mass of visceral organs; hematocrit and hemoglobin content; plasma osmolality; and plasma concentration of urea, sodium, chloride, and potassium. We found that dehydration caused an increase in the concentration of body fluids, as indicated by virtually all the parameters examined. There was a proportional change in the relative masses of visceral organs, except for the liver and kidneys, which exhibited a decrease in their relative masses greater than the whole-body level of dehydration. Changes - or the preservation — of relative organ masses during dehydration may be explained by organ-specific physiological adjustments in response to the functional stress introduced by the dehydration itself. As dehydration progressed, evaporative water loss diminished and water reabsorption increased. In both cases, the increase in body fluid concentration associated with the dehydration provided the osmotic driver for these changes in water flux. Additionally, dehydration-induced alterations on the cutaneous barrier may also have contributed to the decrease in water flux. Dehydration, therefore, while posing a considerable
\end{abstract}

*Corresponding author; e-mail: rco.anderson@gmail.com.

Physiological and Biochemical Zoology 90(3):313-320. 2017. (C) 2017 by The University of Chicago. All rights reserved. 1522-2152/2017/9003-6092\$15.00. DOI: $10.1086 / 690189$ challenge on the water balance regulation of anurans, paradoxically facilitates water conservation and absorption.

Keywords: amphibians, Anura, evaporative water loss, rehydration, water balance.

\section{Introduction}

An inherent threat to amphibians thriving in terrestrial habitats is the potential risk of excessive water loss due to evaporation through the integument (Hillman et al. 2009). Indeed, amphibians usually have a highly permeable skin and, in most instances, exhibit relatively high rates of evaporative water loss (EWL; Wygoda 1984; Lillywhite 2006). In some terrestrial and many arboreal species, however, skin resistance $\left(R_{\mathrm{s}}\right)$ to evaporation may be considerably increased (Young et al. 2005; Wells 2007) and, in exceptional cases, be comparable to those exhibited by reptiles (Shoemaker et al. 1972; Wygoda 1984; Lillywhite 2006). In addition, rates of water uptake (WU) through the skin tend to be higher in terrestrial species compared with aquatic ones (Mullen and Alvarado 1976; Shoemaker and Nagy 1977; but see exceptions in Main and Bentley 1964), possibly enhancing water absorption for the former while preventing excessive water influx for the latter. Rates of EWL and WU are common parameters experimentally examined in studies focusing on aspects of water balance in amphibians, especially in anurans (Bentley and Yorio 1979; Brekke et al. 1991; Hillyard et al. 1998).

Although amphibians exhibit a number of morphological, physiological, and behavioral modifications to prevent excessive water loss (Shoemaker et al. 1992; Jørgensen 1997; Lillywhite 2006), they are bound to experience some level of dehydration whenever water access is limited, be it by a seasonal climatic restriction or by the animals being active away from water sources (see Tracy et al. 2014). Therefore, a high tolerance to dehydration is a widespread feature found in terrestrial anurans (Katz 1989; Jørgensen 1997; Wells 2007), with some species tolerating losses up to $30 \%-50 \%$ of their own body masses (Krakauer 1970; McNab 2002; Hillman et al. 2009). Dehydration is accompanied by the concentration of body fluids (Shoemaker 1964; Degani et al. 1983), with increases in the blood content of some important ions (such as sodium, chloride, and potassium) and metabolites (such as urea; Shoemaker 1964; Alvarado 1972; Hillman 1978; Degani et al. 1983, 1984; Degani and Warburg 1984). Similarly, dehydration causes hematocrit (Hct) and hemoglobin content ([Hb]) to increase 
(Hillman et al. 2009), which may compromise metabolic and cardiovascular capacities (Hillman 1978, 1987), with negative consequences for organs and muscle functions (Hillman 1978, 1987). Finally, visceral organs masses are affected by dehydration, although this effect may vary among different organs (Churchill and Storey 1994).

Considering the physiological consequences of water deficit, it seems natural that dehydration is undisputedly assumed as detrimental for the amphibians. However, while dehydration certainly impacts negatively the water balance of terrestrial anurans, the concentration of body fluids associated with the dehydration bear the potential to influence the water exchange through their skin in a manner that is convenient for water conservation and absorption. More specifically, as body fluids become more concentrated, a decrease in EWL and an increase in WU could be anticipated. While the latter effects have been extensively documented for a few anuran species - particularly on dry habitats, fossorial habits, and/or undergoing seasonal aestivation (McClanahan and Baldwin 1969; Ruibal et al. 1969; Shoemaker et al. 1969; Abe 1994; Cartledge et al. 2006; Muir et al. 2007; Carvalho et al. 2010) - the potential effects of dehydration on EWL have rarely been assessed (Thorson 1956), and its ecological implications remain largely neglected. Therefore, the primary goal of our study was to explicitly test the potential effects of dehydration on organismal parameters relevant to the maintenance of water balance in an anuran species. Hence, we first examined the consequences of graded levels of dehydration to changes in body fluids - including osmolality (Osm), Hct, $[\mathrm{Hb}]$, and plasma concentrations of sodium, chloride, potassium, and urea - and to the relative masses of visceral organs. Second, we measured the rates of EWL and WU for the same graded levels of dehydration and examined the potential relationships between these rates and the respective changes in body fluids and organ masses. The species chosen to carry out this investigation was the cururu toad, Rhinella schneideri (Werner 1894; Anura, Bufonidae), and the levels of dehydration ranged from fully hydrated to dehydration at $90 \%, 80 \%$, and $70 \%$ of their fully hydrated body masses. We chose this toad species because they are primarily terrestrial and, although found in relatively mesic habitats, are commonly found in open areas (Norman 1994). Also, R. schneideri undergoes seasonal aestivation, spending the dry/cold months buried shallowly in the soil or under debris (Noronha-de-Souza et al. 2015). In both cases, this toad species is potentially exposed to the risk of dehydration.

\section{Methods}

Study Animals

Rhinella schneideri is a large-bodied toad widely distributed in South America from north and central Argentina, central Bolivia, Paraguay, Uruguay, and throughout Brazil. Along its distribution area, $R$. schneideri occupies open and seasonally dry habitats (such as the Chaco and the Cerrado domains) but also humid forested areas (such as the Atlantic Rain Forest; Pramuk 2006). They are nocturnal and predominantly terrestrial, and they feed mostly on arthropods (Batista et al. 2011). The breeding season occurs from October to April (Norman 1994).

We collected 40 adult specimens (body mass $=177.28 \pm 83.32 \mathrm{~g}$ [mean $\pm \mathrm{SD}$ ]), including 29 males and 11 females, in the municipality of Barbosa, state of São Paulo, Brazil $\left(21.25048^{\circ} \mathrm{S}\right.$, $49.92132^{\circ} \mathrm{W}$; datum: WGS84; elevation: $371 \mathrm{~m}$ ), on September 30 and November 1, 2013. We transported the toads to the Laboratory of Comparative Animal Physiology, Universidade Estadual Paulista (UNESP), in the municipality of Rio Claro, state of São Paulo, Brazil, about $350 \mathrm{~km}$ from the collection site. In the laboratory, toads were maintained individually in plastic cages $(20 \mathrm{~cm} \times 30 \mathrm{~cm} \times 70 \mathrm{~cm})$ provided with shelter and a bowl full of water kept inside a room with a controlled temperature $\left(23^{\circ} \pm\right.$ $2^{\circ} \mathrm{C}$ ) and natural photoperiod. We monitored toads daily and fed them crickets every other day, except $3 \mathrm{~d}$ before the experiments. First trials began within 3-7 d after toads arrived at the laboratory, and $40 \mathrm{~d}$ was the total time until the end of all experiments. Before starting each experiment, we always weighed the toads, and their body masses varied $4.1 \% \pm 4.3 \%$ from the first day in captivity to the last one. The permit for animal collection was issued by the Instituto Chico Mendes da Conservação da Biodiversidade, Brazil (permit 35081-3), and all experimental protocols were approved by the UNESP Ethical Committee in Animal Experimentation (Comissão de Ética no Uso de Animais; permit 2570/22).

\section{Dehydration Protocol}

We randomly divided the toads into four experimental groups of 10 individuals, and each of these groups was submitted to a different level of dehydration, varying from fully hydrated (100\%) to animals dehydrated until they have lost $10 \%$ ( $90 \%$ hydrated), $20 \%$ ( $80 \%$ hydrated), or $30 \%$ ( $70 \%$ hydrated) of their initial fully hydrated body masses (table 1 ). The body masses at full hydration were determined by placing individual toads in containers filled with $2 \mathrm{~cm}$ of distilled water, which allowed for direct contact between the water and the pelvic region. After 60 min under this condition, we emptied the urinary bladder of the toads by gently pressing the pelvic region and weighed them $( \pm 0.01 \mathrm{~g})$; the weights found under this protocol were accepted as the body mass at full hydration. Following the determination of the fully hydrated body masses, except for $100 \%$, we proceeded to the dehydration protocol until the desired level of dehydration was attained. To promote dehydration, toads were placed individually in a wind tunnel (airflow of $2.5 \pm 0.5 \mathrm{~m} \mathrm{~s}^{-1}$ ) at $25^{\circ} \mathrm{C}$ and a relative humidity of $50 \% \pm 5 \%$. Under these conditions, toads lost water at an average of $10 \mathrm{~g} \mathrm{~h}^{-1}$.

Once the dehydration level desired was attained, toads were subjected to the measurements of EWL and WU rates. Afterwards, we returned them to their maintenance cages and let them recover for $7 \mathrm{~d}$. After this period, we submitted the toads to a second dehydration protocol at the same dehydration level they were previously tested and observing the same procedures already described. At this time, immediately after they reached the dehydration level desired, toads were euthanized with an injection of $1 \mathrm{~mL}$ of benzocaine $2 \%$ into the brain via foramen mag- 
Table 1: Standard and dehydrated mass, evaporative water loss, skin resistance, and water uptake of Rhinella schneideri at different levels of dehydration (mean $\pm \mathrm{SD}$ )

\begin{tabular}{lcccc}
\hline & $100 \%$ & $90 \%$ & $80 \%$ & $70 \%$ \\
\hline Standard mass $(\mathrm{g})$ & $174.41 \pm 69.74$ & $214 \pm 116.11$ & $161.11 \pm 84.47$ & $175.88 \pm 31.83$ \\
Dehydrated mass $(\mathrm{g})$ & $\ldots$ & $192.75 \pm 105.09$ & $128.89 \pm 67.58$ & $123.22 \pm 22.28$ \\
Evaporative water loss $\left(\mu \mathrm{g} \mathrm{cm}^{-2} \mathrm{~s}^{-1}\right)$ & $1.8 \pm .31^{\mathrm{A}}$ & $1.54 \pm .29^{\mathrm{B}}$ & $1.40 \pm .13^{\mathrm{BC}}$ & $1.27 \pm .17^{\mathrm{C}}$ \\
Skin resistance $\left(\mathrm{s} \mathrm{cm}^{-1}\right)$ & $1.12 \pm .68^{\mathrm{A}}$ & $1.49 \pm .98^{\mathrm{A}}$ & $3.22 \pm 1.3^{\mathrm{B}}$ & $4.57 \pm 1.85^{\mathrm{C}}$ \\
Water uptake $\left(\mu \mathrm{g} \mathrm{cm}^{-2} \mathrm{~s}^{-1}\right)$ & $51.06 \pm 24.65^{\mathrm{A}}$ & $118.75 \pm 38.75^{\mathrm{B}}$ & $211.27 \pm 86.87^{\mathrm{C}}$ & $280.61 \pm 107.62^{\mathrm{C}}$ \\
\hline
\end{tabular}

Note. Different letters indicate significant differences among treatments.

num. After the toads ceased to respond to external stimulation, usually within less than $1 \mathrm{~min}$, we opened their body cavity and collected blood samples directly from the truncus arteriosus and dissected the visceral organs to determine their masses.

Evaporative Water Loss, Skin Resistance, and Water Uptake

We measured rates of EWL using an automated open flow system. After weighing the toads $( \pm 0.01 \mathrm{~g})$, we placed them individually in a circular polyvinyl chloride (PVC) chamber $(16 \mathrm{~cm}$ diameter $\times 8 \mathrm{~cm}$ high, volume of $1 \mathrm{~L}$ ) connected to an air pump combined to a mass flow meter (SS-3 Subsampler, Sable Systems) that provided a stable airflow current of $21.66 \mathrm{~cm}^{3} \mathrm{~s}^{-1}$. The relative humidity of this airflow was controlled at $30 \%$ by an RH/Dewpoint Controller (DG-4, Sable Systems) and was directed into the incurrent port of the experimental chamber. The airflow excurrent from the chamber was connected to a water vapor analyzer (relative humidity; 300 RH/Dewpoint Analyzer, Sable Systems). Water vapor readings were recorded each second and sent to a computer using a universal interface (UI2, Sable Systems) and analyzed using the Expedata software (Sable Systems). All the experimental setup was maintained inside a temperaturecontrolled chamber $\left(122 \mathrm{FC}\right.$ model, Eletrolab) at $25^{\circ} \mathrm{C}\left( \pm 1^{\circ} \mathrm{C}\right)$.

We calculated the amount of water lost per animal per unit of time from the increment in water content between the airflow upstream (controlled at a relative humidity of $30 \%$ ) and the downstream of the animal chamber. EWL measurements lasted for up to $1 \mathrm{~h}$ per individual, and for the subsequent calculations, we selected a period of steady-state readings lasting for at least $10 \mathrm{~min}$, typically during the second half of the measurement period. We estimated the exposed surface area of individual toads on the basis of their body masses (McClanahan and Baldwin 1969; Young et al. 2005) and the posture assumed by the animals (e.g., Prates and Navas 2009), which we monitored during the experiments. EWL through the respiratory system was assumed to be negligible (Spotila and Berman 1976; Bentley and Yorio 1979; Wygoda 1984) and was not considered in our estimates. We expressed rates of EWL as $\mu \mathrm{g} \mathrm{H}_{2} \mathrm{O} \mathrm{cm}^{-2} \mathrm{~s}^{-1}$.

We calculated the resistance to water efflux $\left(\mathrm{s} \mathrm{cm}^{-1}\right)$ as the reciprocal of the mass transfer coefficient $\left(\mathrm{cm} \mathrm{s}^{-1}\right)$, which was estimated on the basis of the EWL measurements. Total resistance $\left(R_{\mathrm{t}}\right)$ incorporates the boundary layer resistance $\left(R_{\mathrm{b}}\right)$ with the resistance offered by any existing barrier, such as the skin $\left(R_{\mathrm{s}}\right)$.
Thus, in order to estimate the resistance of the toads' skin to water evaporation, we measured EWL rates for similar-sized $3 \%$ agar replicas of each individual toad, which are entirely determined by $R_{\mathrm{b}}$. Thereafter, by subtracting the agar model resistances $\left(R_{\mathrm{b}}\right)$ from the $R_{\mathrm{t}}$ estimated for the toads, we were able to isolate $R_{\mathrm{s}}$ (see calculation details in Shoemaker et al. 1992; Young et al. 2005).

Immediately after EWL measurements, we transferred the toads to a PVC chamber identical to the one they were kept but filled with tap water to a depth of $1 \mathrm{~cm}$, which was sufficient to cover their ventral abdominal region (Cree 1988). Toads were then carefully blotted with paper tissue and weighed $( \pm 0.01 \mathrm{~g})$ six consecutive times at 2-min intervals. We calculated rates of WU from the linear regression between body mass increments against time. Using the estimated surface area in contact with the water (same equations as above; McClanahan and Baldwin 1969; Young et al. 2005), we calculated the rate of WU per unit area per time and expressed it as $\mu \mathrm{g} \mathrm{H}_{2} \mathrm{O} \mathrm{cm}{ }^{-2} \mathrm{~s}^{-1}$.

\section{Body Fluids}

Hct was determined after $10 \mathrm{~min}$ of blood centrifugation at 10,000 rpm (Micro Spin micro hematocrit centrifuge) immediately after blood collection. [Hb] was determined posteriorly on frozen samples of whole blood. Osm, urea, and ions were similarly determined posteriorly on frozen samples of plasma, harvested after centrifugation of the blood at 13,000 rpm for $5 \mathrm{~min}$. Samples were stored at $-80^{\circ} \mathrm{C}$.

[Hb], chloride, and urea were determined by colorimetry using commercially available analytical kits (BioClin K023/K029, BioClin K050, and Vitro Urea LiquiUV, respectively) in a spectrophotometer (Femto 600Plus) in triplicate. Osm was determined by the freezing point depression using a Knauer SemiMicro osmometer (NS 19292), in duplicate. Sodium and potassium concentrations were determined by inductively coupled plasma optic emission spectroscopy (ICP OES, iCAP, 6000 Series ICP Spectrometer, Thermo Scientific) before previous acidic digestion of samples in a microwave oven (Berghof, SW-4).

\section{Visceral Organs}

Ventricle, liver, kidneys, spleen, stomach, and intestine were carefully dissected and cleaned from any content or peripheral tissues and blotted with paper tissue previously of being weighed 


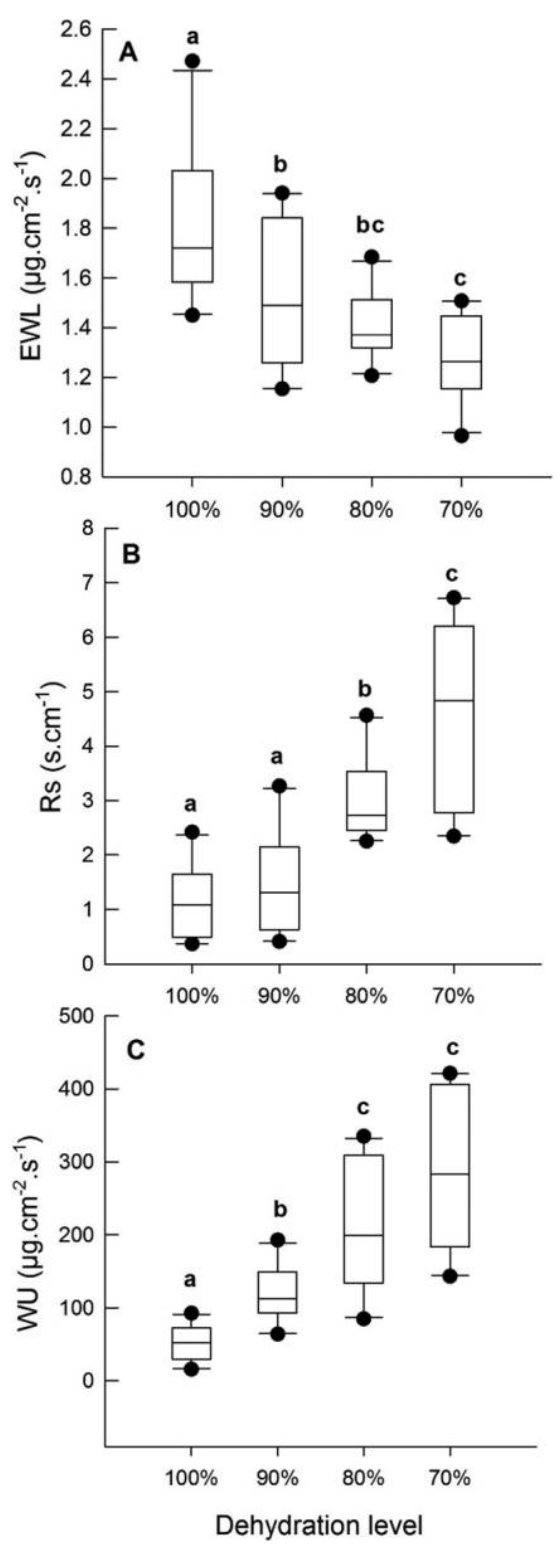

Figure 1. Evaporative water loss $(\mathrm{EWL} ; A)$, skin resistance $\left(R_{\mathrm{s}} ; B\right)$, and water uptake (WU; $C$ ) of Rhinella schneideri at different levels of dehydration. Rates of EWL were measured at constant air temperature $\left(25^{\circ} \mathrm{C}\right)$ and relative humidity $(30 \%)$. Box plot borders represent the second and third interquartile range, lines indicate medians, and whiskers indicate the range of the data. Different letters indicate significant differences (Holm-Sidak test, $P<0.05)$, and circles are outliers.

( $\pm 0.0001 \mathrm{~g}$ ). Relative organ masses were determined by equating organ mass to body mass.

\section{Data Analyses}

We used one-way ANOVA to examine for statistical differences among the experimental groups. We considered dehydration level as a factor and EWL, $R_{\mathrm{s}}, \mathrm{WU}, \mathrm{Hct}$, [Hb], organ masses, and concentrations of urea and ions as the response variables.
Before the ANOVA, we evaluated the parametric premises of normality (Shapiro-Wilk) and equality of variances (Levene's test). If data did not conform to premises, we tried to log transform to improve the residual distribution. If log transformation failed to adjust the data, we performed the Kruskal-Wallis ANOVA by ranks test. We used the Holm-Sidak test for post hoc multiple comparisons. All tests followed Zar (1999), and data are presented as means \pm SD. The level of significant differences was considered at $\alpha=0.05$. Since sex had no effect at any vari-
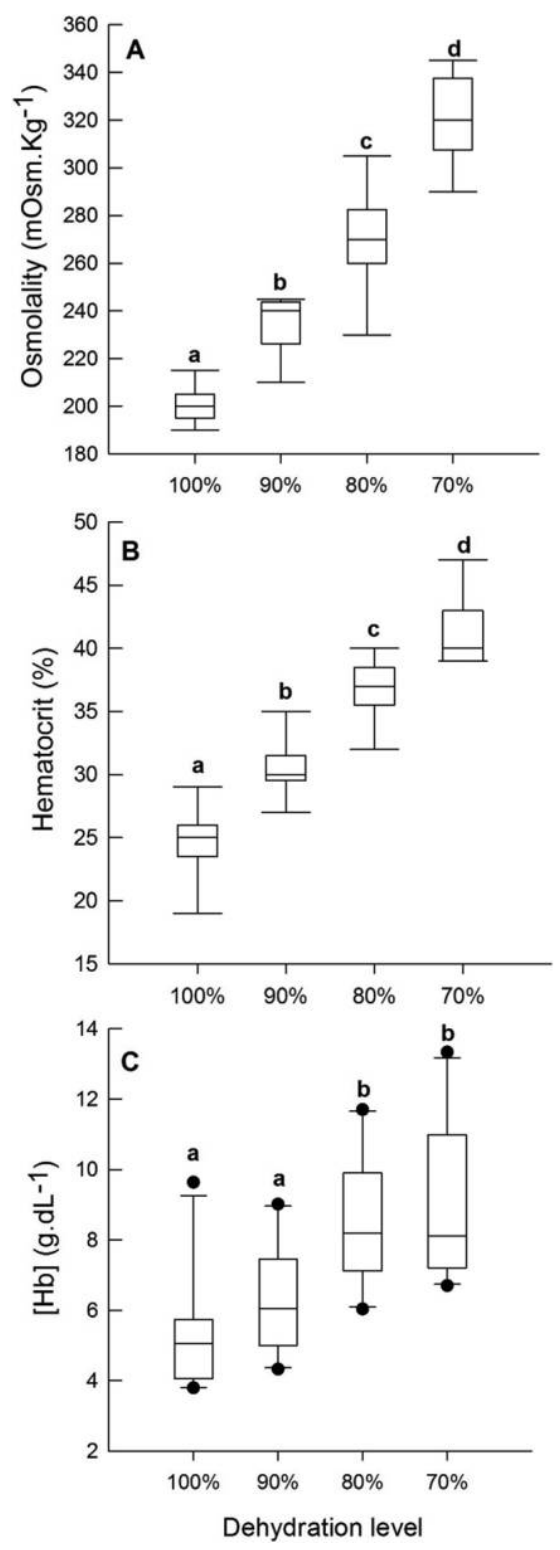

Figure 2. Plasma osmolality $(A)$, hematocrit $(B)$, and hemoglobin concentration $(C)$ of Rhinella schneideri at different levels of dehydration. All the procedures were in a room with an air temperature of $25^{\circ} \pm 2^{\circ} \mathrm{C}$. Box plot borders represent the second and third interquartile range, lines indicate medians, and whiskers indicate the range of the data. Different letters indicate significant differences (Holm-Sidak test, $P<0.05$ ), and circles are outliers. 
Table 2: Hematocrit (\%) and concentrations of hemoglobin ([Hb]), urea, and ions (sodium, chloride, and potassium) in blood (plasma) of Rhinella schneideri at different levels of dehydration (mean $\pm \mathrm{SD}$ )

\begin{tabular}{lcccc}
\hline & $100 \%$ & $90 \%$ & $80 \%$ & $70 \%$ \\
\hline Sodium $\left(\mathrm{mmol} \mathrm{L}^{-1}\right)$ & $97.93 \pm 10.93^{\mathrm{A}}$ & $106.34 \pm 9.87^{\mathrm{A}}$ & $120.77 \pm 23.2^{\mathrm{B}}$ & $161.83 \pm 12.72^{\mathrm{C}}$ \\
Potassium $\left(\mathrm{mmol} \mathrm{L}^{-1}\right)$ & $2.69 \pm .49$ & $2.725 \pm .37$ & $2.65 \pm .43$ & $2.97 \pm 1.28$ \\
Chloride $\left(\mathrm{mEq} \mathrm{L}^{-1}\right)$ & $58.47 \pm 3.49^{\mathrm{A}}$ & $64.25 \pm 5.63^{\mathrm{A}}$ & $78.66 \pm 8.71^{\mathrm{B}}$ & $98.63 \pm 8.37^{\mathrm{C}}$ \\
Urea $\left(\mathrm{mmol} \mathrm{L}^{-1}\right)$ & $17.43 \pm 6.79^{\mathrm{A}}$ & $32.25 \pm 6.58^{\mathrm{A}}$ & $46.55 \pm 10.54^{\mathrm{B}}$ & $99.75 \pm 24.37^{\mathrm{B}}$ \\
Hematocrit $\%)$ & $26.6 \pm 5.18^{\mathrm{A}}$ & $31.4 \pm 3.68^{\mathrm{B}}$ & $35.7 \pm 4.3^{\mathrm{C}}$ & $40.1 \pm 4.38^{\mathrm{D}}$ \\
{$[\mathrm{Hb}]\left(\mathrm{g} \mathrm{dL}^{-1}\right)$} & $6.005 \pm 2.91^{\mathrm{A}}$ & $6.28 \pm 2.16^{\mathrm{A}}$ & $7.95 \pm 2.39^{\mathrm{B}}$ & $8.91 \pm 2.26^{\mathrm{B}}$ \\
\hline
\end{tabular}

Note. Different letters indicate significant differences among treatments.

able measured ( $t$-test: $P>0.05$ in all variables), we did not include it as a factor in our data analysis.

\section{Results}

Evaporative Water Loss, Skin Resistance, and Water Uptake

Rates of EWL differed among the experimental groups $\left(F_{3,38}=\right.$ 9.65, $P<0.001)$, decreasing with the increase in dehydration level (fig. $1 A$; table 1$)$, except between $90 \%$ and $80 \%(P=0.081)$ and between $80 \%$ and $70 \%(P=0.304) . R_{\mathrm{s}}$ also differed among groups $\left(H_{3}=30.05, P \leq 0.001\right)$, increasing concurrently with dehydration (fig. $1 B$; table 1), except between $100 \%$ and $90 \%(P>0.05)$. Rates of WU differed among the experimental groups $\left(F_{3,38}=\right.$ 28.77, $P<0.001)$, decreasing with the increase in dehydration level (fig. $1 C$; table 1), except between $80 \%$ and $70 \%(P=0.15)$.

\section{Body Fluids}

$\operatorname{Osm}\left(F_{3,29}=124.49, P<0.001\right.$; fig. $\left.2 A\right)$ and $\operatorname{Hct}\left(F_{3,32}=59.35\right.$, $P<0.001$; fig. $2 B$ ) increased concurrently with dehydration (post hoc tests: $P<0.001$ in all pairwise multiple comparisons). [Hb] increased with dehydration $\left(F_{3,33}=9.95, P<0.001\right.$; fig. $\left.2 C\right)$ but not significantly between $100 \%$ and $90 \%(P=0.23)$ and also not between $80 \%$ and $70 \%(P=0.42)$. Urea concentration was different among the groups $\left(H_{3}=28.9, P<0.001\right)$, increasing with dehydration, except between $100 \%$ and $90 \%(P=0.31)$ and between $80 \%$ and $70 \%(P=0.33)$. Sodium concentration increased with dehydration $\left(F_{3,35}=29.58, P<0.001\right)$, except between $100 \%$ and $90 \%(P=0.23)$. Chloride concentration increased with dehydration $\left(F_{3,34}=59.14, P<0.001\right.$; table 2$)$, except between $100 \%$ and $90 \%(P=0.096)$. Potassium concentration did not change among experimental groups $\left(H_{3}=2.01\right.$, $P=0.56$; table 2).

\section{Visceral Organs}

We found no differences among experimental groups in relative mass of ventricle, spleen, stomach, and intestine $(P>0.05$ in all cases; fig. 3). The relative mass of liver decreased with the increase in dehydration level $\left(F_{3,34}=21.45, P<0.001\right)$ but not significantly between $90 \%$ and $80 \%(P=0.07$; table 3$)$. The relative mass of

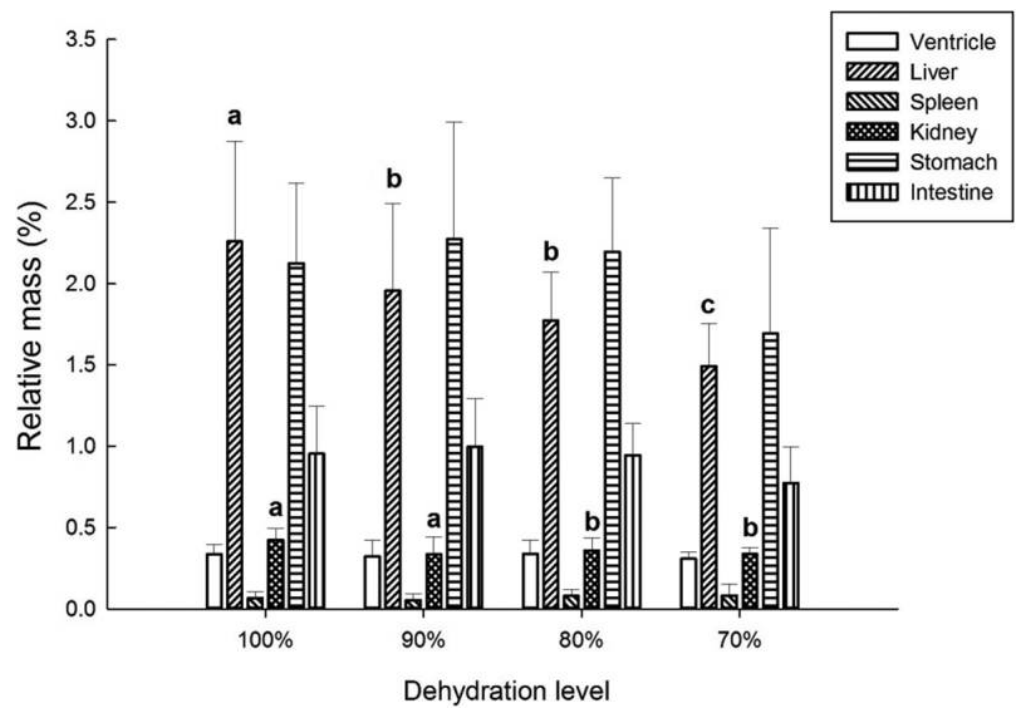

Figure 3. Relative masses (mean $+\mathrm{SD}$ ) of visceral organs of Rhinella schneideri at different levels of dehydration. Different letters indicate significant differences $(P<0.05)$. Note that only the liver and kidneys masses were significantly different among dehydration levels. 
Table 3: Relative mass of visceral organs of Rhinella schneideri at different levels of dehydration $($ mean $\pm \mathrm{SD})$

\begin{tabular}{lcccc}
\hline & $100 \%$ & $90 \%$ & $80 \%$ & $70 \%$ \\
\hline Ventricle & $.335 \pm .058$ & $.322 \pm .103$ & $.338 \pm .085$ & $.307 \pm .039$ \\
Liver & $2.521 \pm .297^{\mathrm{A}}$ & $2.086 \pm .364^{\mathrm{B}}$ & $1.843 \pm .210^{\mathrm{B}}$ & $1.448 \pm .236^{\mathrm{C}}$ \\
Spleen & $.065 \pm .04$ & $.05 \pm .036$ & $.079 \pm .036$ & $.082 \pm .071$ \\
Kidneys & $.423 \pm .070^{\mathrm{A}}$ & $.379 \pm .059^{\mathrm{A}}$ & $.329 \pm .053^{\mathrm{B}}$ & $.337 \pm .039^{\mathrm{B}}$ \\
Stomach & $2.125 \pm .494$ & $2.273 \pm .717$ & $2.195 \pm .453$ & $2.007 \pm .649$ \\
Intestine & $.953 \pm .293$ & $.996 \pm .292$ & $.944 \pm .194$ & $.774 \pm .224$ \\
\hline
\end{tabular}

Note. Different letters indicate significant differences among treatments.

the kidneys decreased with the increase in dehydration level $\left(F_{3,37}=5.87, P=0.002\right)$, but this effect was found to be statistically significant only between $100 \%$ compared with $80 \%$ $(P<0.001)$ and $70 \%(P<0.01$; table 3$)$.

\section{Discussion}

As expected, dehydration in Rhinella schneideri was accompanied by the concentration in body fluids as indicated by the concurrent increases in Osm, Hct, [Hb], [urea], and ions. These effects have been previously observed in many other anuran species (Ruibal 1962; Shoemaker 1964; Ruibal et al. 1969; Shoemaker et al. 1969; Shoemaker and Nagy 1977; Degani et al. 1983; Jørgensen 1997; Lillywhite 2006) and, in some cases, were explicitly interpreted in terms of their water exchange implications. For example, ions and urea concentrations are well known to increase in species estivating burrowed in the soil (see Ruibal et al. 1969; Degani et al. 1983; Muir et al. 2007) or exposed to hyperosmotic (saline) conditions (Katz 1989; Hoffman and Katz 1997). In both cases, the increased concentration in body fluids is largely accepted as convenient to the maintenance of an adequate water balance by reducing the osmotic potential between the animal and the surrounding environment (Shoemaker 1964; Ruibal et al. 1969; Shoemaker et al. 1969). This would diminish the potential for water loss and, if the osmotic potential becomes reversed, even allow for water absorption from the surrounding medium (Ruibal et al. 1969; Shoemaker et al. 1969; Hoffman and Katz 1997, 1999). In agreement with these previous studies, our results clearly show that the increase in plasma Osm accelerated water absorption in R. schneideri. Even though this species thrives in a relatively mesic habitat, it often forages in open dry areas and aestivates during the dry/cold season at the region; therefore, dehydration-induced changes in WU probably confer to $R$. schneideri the same beneficial effects just mentioned.

The potential influences of dehydration on the rates of EWL have rarely been discussed for anuran amphibians. In fact, only Thorson (1956) directly evaluated the effects of desiccation on the rates of EWL in three different anuran species. However, differently from the present study, Thorson (1956) did not find a consistent relationship between dehydration levels with the measured rates of EWL for any of the species examined. Instead, EWL oscillated without any apparent relationship with the pro- gression of dehydration (Thorson 1956). Because the gravimetric method adopted by Thorson (1956) did not allow for the instantaneous measurement of EWL rates, we suspect that some of his results may have been confounded by postural and behavioral responses associated with dehydration rather than changes in skin permeability per se. Indeed, dehydration often induced postural changes and locomotor escape responses in anuran amphibians that are well known to significantly affect the rates of EWL (Drewes et al. 1977; Pough et al. 1983). Such effects were clearly identifiable under our methodological approach; therefore, we were able to eliminate this confounding factor from our EWL calculations. As a result, the rates of EWL in R. schneideri were found to be strictly associated with the level of dehydration and to the concurrent changes in body fluid concentration. Thus, at least partially, the reduction of EWL rates as the body fluids become more concentrated may be attributed to the osmotic influence on the water vapor pressure of the evaporating surface (see Al-Shammiri 2002). Additionally, dehydration causes the outer cell layers of the anuran skin to become compacted (Lillywhite 1975) and, therefore, may also contribute to the decrease in EWL rates under such conditions (see Lillywhite 1975).

Our results-combined with the observation that terrestrial anurans routinely experience some level of dehydration while active in the field (Ruibal 1962; Ruibal et al. 1969; Shoemaker et al. 1969; Tracy et al. 2014)—have important ecophysiological implications. Anurans engaging in activities away from water sources are potentially exposed to the risk of losing excessive amounts of water by evaporation. However, as we show here, as dehydration progresses, the resulting concentration in body fluids counteracts further water loss and will facilitate a future bout event of water reabsorption when opportune circumstances occur. As a result, these dehydration side effects may allow for the extension of the period that terrestrial anurans spend active far from water sources or even promote a better chance of survival under more extreme conditions associated with water restriction. This scenario, however, implicitly assumes that organismal performance would not be importantly compromised by dehydration. Although no information about this aspect is available under natural settings, locomotor performance (Preest and Pough 1989; Titon et al. 2010) and the relative success in prey detection/capture (Preest and Pough 2003) indeed exhibit low sensitivity to dehydration in toads under laboratory conditions. 
During dehydration, different organs may lose water at different rates, which will be reflected in changes of their relative masses (Hillman 1980; Churchill and Storey 1996). For R. schneideri, the only organs that lost water in disproportion to the whole-body level of dehydration were the liver and the kidneys. In both cases, the relative masses of the organs were reduced as dehydration became more severe. Although the causal mechanisms of this response are hard to isolate, we know that the liver mobilizes glucose and urea during dehydration states (Churchill and Storey 1994, 1995); therefore, this response may add an extra loss of mass on top of that exclusively related to a decrease in water content. During water deprivation, urine production is reduced or ceased in anurans; therefore, this may account for the decrease observed in the relative mass of the kidneys (Shoemaker and Nagy 1977). The other organs examined (ventricle, spleen, stomach, and intestine) had their relative masses preserved across the different levels of dehydration. Therefore, the changes in the masses for these organs were proportional to the overall level of dehydration and can be attributed to corresponding changes in their water content. The functional implications of alterations in water content experienced by different organs under dehydration states are uncertain and may encompass complex interactions. For example, dehydration imposes an increased workload on the cardiac function because of an increment in blood viscosity associated with the elevation of Hct (see Hillman 1980, 1987; Nikinmaa 1990), which then may interact with the changes in water content of the ventricle (or heart) itself (see also Churchill and Storey 1995). Clearly, the consequences of changes in the water content of individual organs to their respective functional capabilities deserve further investigation.

In summary, the results we found for $R$. schneideri agree with many previous studies relating the effects of dehydration to changes in body fluids and in the mass of visceral organs. While dehydration can be generally accepted as unequivocally deleterious to physiological function, examination of its effects on the rates of water exchange clearly shows that water conservation (i.e., decrease in EWL) and absorption (i.e., increase in WU) were facilitated. The ecological implications of such effects are certainly relevant for the maintenance of adequate water balance in anuran amphibians. Indeed, changes in WU associated with variation in body fluid osmotic potential were long documented as instrumental for assisting water balance in some species, particularly in those inhabiting xeric habitats, with fossorial habits, and/or undergoing seasonal aestivation (Ruibal 1962; McClanahan and Baldwin 1969; Ruibal et al. 1969; Shoemaker et al. 1969; Abe 1994; Carvalho et al. 2010). On the other hand, the potential implications of dehydration-induced changes in EWL on the life history, behavior, and ecophysiology of anurans remain largely uncertain.

\section{Acknowledgments}

We thank Augusto S. Abe for the use of laboratory space and equipment and Ariovaldo P. Cruz-Neto for commenting on an earlier version of the manuscript. We also thank Celso Gavira and Rodrigo Gavira for granting us access to the collection site and helping with animal collection. This study was supported by the São Paulo Research Foundation (FAPESP; 10/20061-6 to R.P.B., 13/04190-9 to D.V.A.) and the National Council for Scientific and Technological Development (CNPq; 302045/2012-0 and 306811/2015-4 to D.V.A., 13/14-25780 to R.C.O.A.).

\section{Literature Cited}

Abe A.S. 1994. Estivation in South American amphibians and reptiles. Braz J Med Biol Res 28:1241-1247.

Al-Shammiri M. 2002. Evaporation rate as a function of water salinity. Desalination 150:189-203.

Alvarado R.H. 1972. The effects of dehydration on water and electrolytes in Ambystoma tigrinum. Physiol Zool 45:43-53.

Batista R.C., C. Brito-de-Carvalho, E.B. Freitas, S.C. Franco, C.C. Batista, W.A. Coelho, and R.G. Faria. 2011. Diet of Rhinella schneideri (Werner, 1894) (Anura: Bufonidae) in the Cerrado, Central Brazil. Herpetol Notes 4:17-21.

Bentley P.J. and T. Yorio. 1979. Evaporative water loss in anuran amphibia: a comparative study. Comp Biochem Phvsiol A 62: 1005-1009.

Brekke D.R., S.D. Hillyard and R.M. Winokur. 1991. Behavior associated with the water absorption response by the toad, Bufo punctatus. Copeia 2:393-401.

Cartledge V.A., P.C. Withers, K.A. McMaster, G.G. Thompson, and S.D. Bradshaw. 2006. Water balance of field-excavated aestivating Australian desert frogs, the cocoon-forming Neobatrachus aquilonius and the non-cocooning Notaden nichollsi (Amphibia: Myobatrachidae). LExp Biol 209:3309-3321.

Carvalho J.E., C.A. Navas, and I.C. Pereira. 2010. Energy and water in aestivating amphibians. Pp. 141-169 in C.A. Navas and J.E. Carvalho, eds. Aestivation. Springer, Berlin.

Churchill T.A. and K.B. Storey. 1994. Effects of dehydration on organ metabolism in the frog Pseudacris crucifer: hyperglycemic responses to dehydration mimic freezing-induced cryoprotectant production. I Comp Physiol B 164:492-498.

1995. Metabolic effects of dehydration on an aquatic frog, Rana pipiens. LExp Biol 198:147-154.

- 1996. Organ metabolism and cryoprotectant synthesis during freezing in spring peepers Pseudacris crucifer. Copeia 3:517-525.

Cree A. 1988. Water balance responses of the hylid frog Litoria aurea. LExp Zool 247:119-125.

Degani G., S. Goldenberg, and M. Warburg. 1983. Changes in ion, urea concentrations and blood plasma osmolarity of Pelobates syriacus juveniles under varying conditions. Comp Biochem Physiol A 75:619-623.

Degani G., N. Silanikov, and A. Shkolnik. 1984. Adaptation of green toad (Bufo viridis) to terrestrial life by urea accumulation. Comp Biochem Physiol A 77:585-587.

Degani G. and M. Warburg. 1984. Changes in concentrations of ions and urea in both plasma and muscle tissue in a dehydrated hylid anuran. Comp Biochem Phvsiol A 77:357-360. Drewes R.C., S.S. Hillman, R.W. Putnam, and O.M. Sokol. 1977. Water, nitrogen and ion balance in the African treefrog Chiromantis petersi boulenger (Anura: Rhacophoridae), 
with comments on the structure of the integument. $\underline{L}$ Comp Phvsiol B 116:257-267.

Hillman S.S. 1978. Some effects of dehydration on internal distributions of water and solutes in Xenopus laevis. Comp Biochem Phvsiol A 61:303-307.

. 1980. Physiological correlates of differential dehydration tolerance in anuran amphibians. Copeia 1:125-129. - 1987. Dehydrational effects on cardiovascular and metabolic capacity in two amphibians. Physiol Zool 5:608-613.

Hillman S.S., P.C. Withers, R.C. Drewes, and S.D. Hillyard. 2009. Ecological and environmental physiology of amphibians. Oxford University Press, Oxford.

Hillyard S.D., K. Hoff, and C. Propper. 1998. The water absorption response: a behavioral assay for physiological processes in terrestrial amphibians. Physiol Zool 71:127-138.

Hoffman J. and U. Katz. 1997. Salt and water balance in the toad Bufo viridis during recovery from two different osmotically stressful conditions. Comp Biochem Physiol A 117:147-154.

. 1999. Elevated plasma osmotic concentration stimulates water absorption response in a toad. LExp Zool 284:168-173.

Jørgensen C.B. 1997. 200 years of amphibian water economy: from Robert Townson to the present. Biol Rev 72:153-237.

Katz U. 1989. Strategies of adaptation to osmotic stress in anuran amphibia under salt and burrowing conditions. Comp Biochem Physiol A 93:499-503.

Krakauer T. 1970. Tolerance limits of the toad, Bufo marinus, in south Florida. Comp Biochem Physiol 33:15-26.

Lillywhite H.B. 1975. Physiological correlates of basking in amphibians. Comp Biochem Phvsiol A 52:323-330.

- 2006. Water relations of tetrapod integument. L Exp Biol 209:202-226.

Main A.R. and P.J. Bentley. 1964. Water relations of Australian burrowing frogs and tree frogs. Ecology 2:379-382.

McClanahan L. and R. Baldwin. 1969. Rate of water uptake through the integument of the desert toad, Bufo punctatus. Comp Biochem Physiol 28:381-389.

McNab B.K. 2002. The physiological ecology of vertebrates: a view from energetics. Cornell University Press, Ithaca, NY.

Muir T.J., J.P. Costanzo and R.E. Lee Jr. 2007. Osmotic and metabolic responses to dehydration and urea-loading in a dormant, terrestrially hibernating frog. L Comp Physiol B 177: 917-926.

Mullen T.L. and R.H. Alvarado. 1976. Osmotic and ionic regulation in amphibians. Physiol Zool 1:11-23.

Nikinmaa M. 1990. Vertebrate red blood cells: adaptations of function to respiratory requirements. Springer, Berlin.

Norman D.R. 1994. Anfibios y reptiles del Chaco paraguayo. Tomo 1. San José, Costa Rica.

Noronha-de-Souza C.R., R.P. Bovo, L.H. Gargaglioni, D.V. Andrade, and K.C. Bícego. 2015. Thermal biology of the toad Rhinella schneideri in a seminatural environment in southeastern Brazil. Temperature 2:554-562.

Pough F.H., T.L. Taigen, M.M. Stewart, and P.F. Brussard. 1983. Behavioral modification of evaporative water loss by a Puerto Rican frog. Ecology 64:244-252.
Pramuk J.B. 2006. Phylogeny of South American Bufo (Anura: Bufonidae) inferred from combined evidence. Zool I Linn Soc 146:407-452.

Prates I. and C.A. Navas. 2009. Cutaneous resistance to evaporative water loss in Brazilian Rhinella (Anura: Bufonidae) from contrasting environments. Copeia 3:618-622.

Preest M.R. and F.H. Pough. 1989. Interaction of temperature and hydration on locomotion of toads. Funct Ecol 3:693-699.

. 2003. Effects of body temperature and hydration state on organismal performance of toads, Bufo americanus. Physiol Biochem Zool 76:229-239.

Ruibal R. 1962. The adaptive value of bladder water in the toad, Bufo cognatus. Physiol Zool 35:218-223.

Ruibal R., L. Tevis Jr., and V. Roig. 1969. The terrestrial ecology of the spadefoot toad Scaphiopus hammondii. Copeia 3:571-584.

Shoemaker V.H. 1964. The effects of dehydration on electrolyte concentrations in a toad, Bufo marinus. Comp Biochem Physiol 13:261-271.

Shoemaker V.H., D. Balding, R. Ruibal, and L.L. McClanahan. 1972. Uricotelism and low evaporative water loss in a South American frog. Science 175:1018-1020.

Shoemaker V.H., S.S. Hillman, S.D. Hillyard, D.C. Jackson, L.L. McClanahan, P.C. Whiters, and M.L. Wygoda. 1992. Exchange of water, ions, and respiratory gases in terrestrial amphibians. Pp. 125-150 in M.E. Feder and W.W. Burggren, eds. Environmental physiology of the amphibians. University of Chicago Press, Chicago.

Shoemaker V.H., L. McClanahan Jr., and R. Ruibal. 1969. Seasonal changes in body fluids in a field population of spadefoot toads. Copeia 3:585-591.

Shoemaker V.H. and K.A. Nagy. 1977. Osmoregulation in amphibians and reptiles. Annu Rev Physiol 39:449-471.

Spotila J.R. and E.N. Berman. 1976. Determination of skin resistance and the role of the skin in controlling water loss in amphibians and reptiles. Comp Biochem Phvsiol A 55: 407-411.

Thorson T.B. 1956. Adjustment of water loss in response to desiccation in amphibians. Copeia 4:230-237.

Titon B., C.A. Navas, J. Jim, and F.R. Gomes. 2010. Water balance and locomotor performance in three species of Neotropical toads that differ in geographical distribution. Comp Biochem Physiol A 156:129-135.

Tracy C.R., T. Tixier, C. Le Nöene, and K.A. Christian. 2014. Field hydration state varies among tropical frog species with different habitat use. Physiol Biochem Zool 87:197-202.

Wells K.D. 2007. The ecology and behavior of amphibians. University of Chicago Press, Chicago.

Wygoda M.L. 1984. Low cutaneous evaporative water loss in arboreal frogs. Phvsiol Zool 57:329-337.

Young J.E., K.A. Christian, S. Donnellan, C.R. Tracy, and D. Parry. 2005. Comparative analysis of cutaneous evaporative water loss in frogs demonstrates correlation with ecological habits. Physiol Biochem Zool 78:847-856.

Zar J.H. 1999. Biostatistical analysis. Prentice Hall, Upper Saddle River, NJ. 